\title{
Vectorial Competence of Aedes aegypti (Linnaeus 1762) Rio de Janeiro Strain, to Dirofilaria immitis (Leidy 1856)
}

\author{
Maria Lúcia Serrão/ ${ }^{+}$, Norma Labarthe*, Ricardo Lourenço-de-Oliveira
}

\begin{abstract}
Laboratório de Transmissores de Hematozoários, Departamento de Entomologia, Instituto Oswaldo CruzFiocruz, Av. Brasil 4365, 21045-900 Rio de Janeiro, RJ, Brasil *Faculdade de Veterinária, Centro de Ciências Médicas, Universidade Federal Fluminense, Niterói, RJ, Brasil
\end{abstract}

\begin{abstract}
Dirofilaria immitis (Leidy 1856), a nematode parasite, is the etiologic agent of canine heartworm disease and mosquitoes are essential intermediate hosts. Mosquito susceptibility to the worms differ with species, strains and also among individuals of the same strain. To evaluate the degree of susceptibility of Rio de Janeiro laboratory raised strain of Aedes aegypti, we fed mosquitoes on canine blood with different densities of microfilariae ( $\mathrm{mf}$ ). There was no significant difference in the rate of development among the three different densities of mf. Infective larvae were found in the head and proboscis of all mosquitoes provided bloodmeals with different densities of mf after the 11th day post-infection. The infection rate of mosquitoes after ingestion of blood containing 3,000 mf/ml, 5,000 mf/ml and 7,000 mfl $\mathrm{ml}$ were $55.3 \%, 66.7 \%$ and $100 \%$, respectively. The vector efficiency indices ranged from 1.6 to 9.3. The finding of $L_{3}$ stage larvae, high infection rates and vector efficiency indices suggest that Ae. aegypti, Rio de Janeiro laboratory strain, is a potential vector of D. immitis, although of low efficiency.
\end{abstract}

Key words: Aedes aegypti - Dirofilaria immitis - heartworm

Dirofilaria immitis (Leidy 1856), a nematode parasite, is the etiologic agent of canine heartworm disease. Mosquitoes are essential intermediate hosts of this parasite. When female mosquitoes take a bloodmeal from a microfilaremic vertebrate host, they ingest microfilariae (mf). Larvae then migrate into the Malpighian tubules where they reside in the cytoplasm of the primary cells. By the sixth day post-infection, larvae migrate from the cells to the lumen of the tubules where they further develop by two molts. After the second molt, the infective larvae migrate through the hemocoel to the cephalic spaces and into the proboscis (Taylor 1960). During subsequent bloodfeeding, the infective larvae escape from the labium and enter the definitive host.

The mortality rate for infected mosquitoes is higher than for uninfected mosquitoes and is probably caused by two factors: (1) the invasion of the Malpighian tubule cells by the microfilarial stage and (2) the escape of the infective larvae from the Malpighian tubules and their subsequent movement to the head and mouthparts via the hemocoel (Kutz \& Dobson 1974). It is known that when the filariae

\footnotetext{
${ }^{+}$Corresponding author and Capes fellowship

Fax: +55-21-710.8825

E-mail: mlserrao@zipmail.com.br

Received 24 July 2000

Accepted 15 February 2001
}

burden in the Malpighian tubules increases, the result is excessive mortality that may approach $100 \%$ (Kershaw et al. 1953, Webber \& Hawking 1955, Christensen 1978). In order to survive long enough to allow the complete development of the helminth and therefore transmit the parasite among definitive hosts, the number of developing filariae in the mosquito must be reduced (Kershaw et al. 1955).

Mosquitoes are able to control the infection by D. immitis through mechanisms that reduce parasite burden by destroying or preventing the development of the nematode, i.e., well developed cibarial armature that inflict larval damage (Bryan et al. 1974, McGreevy et al. 1978), trapping of larvae in the coagulated bloodmeal in the mosquito's midgut (Kartman 1953), oxyhaemoglobin crystals formed by bloodmeal coagulation in the midgut that hinder the movement of $\mathrm{mf}$ and kill them (Nayar \& Sauerman 1975, Lowrie 1991), lysis of larval cuticle by host cells (Talluri \& Cancrini 1994), and encapsulation and/or melanization of the parasite in the Malpighian tubules. This last defense reaction is an important mechanism of refractoriness to $D$. immitis developed by mosquitoes in the genus Aedes (Lindemann 1977, Christensen 1981, Christensen et al. 1989).

Approximately 70 species of mosquitoes belonging to the genera Culex, Aedes, Anopheles, Mansonia, Coquillettidia and Psorophora have been shown to support complete larval development of $D$. immitis in the laboratory (Ludlam et al. 1970), but few of them are efficient natural vec- 
tors of this helminth in nature. The susceptibility differs with the mosquito species, strains of mosquitoes and also among individuals of the same strain (Christensen \& Andrews 1976, Buxton \& Mullen 1981, Christensen \& Sutherland 1984, Apperson et al. 1989). Although Ae. aegypti (Linnaeus 1762) is regarded as an unsuitable natural host of D. immitis, wild and laboratory strains of this species have been used to study the development of the parasite (Buxton \& Mullen 1981, Tolbert \& Johnson 1982, Sauerman \& Nayar 1983). Differences in the susceptibility of various strains of this species to filarial infections in the laboratory have been reported (Chellappah \& Chellappah 1968, Nayar \& Sauerman 1975, Buxton \& Mullen 1981, Sulaiman 1983) and shown that there is a large variation in the susceptibility of the same species of mosquitoes in the experiments carried out in different laboratories (Kartman 1953).

In Brazil, there are four reports of $D$. immitismosquito relationships under experimental conditions. Ae. fluviatilis (Lutz) susceptibility to infection was tested and the authors suggested that, although they were susceptible to some degree, in nature this species is unlikely to be an efficient vector (Kasai \& Williams 1986). The vectorial competence of Ae. scapularis (Rondani 1848) has been made evident by Macêdo et al. (1998). Vector competente of Culex quinquesfasciatus (Say) from different regions of Brazil to $D$. immitis was studied by Ahid et al. (2000). Ae. aegypti vector efficency was shown to be seven times better than $C x$. quinquefasciatus and for that reason, it has better potential than $C x$. quinquefasciatus as a vector of canine heartworm in Maceió (Brito et al. 1999).

This study evaluated the degree of susceptibility of Ae. aegypti, Rio de Janeiro laboratory strain, fed on blood with different densities of mf, to understand its potential use in laboratory studies with D. immitis.

\section{MATERIALS AND METHODS}

Ae. aegypti adult females were reared from eggs from a colony established in 1990 from wild mosquitoes caught in Rio de Janeiro, RJ. Eggs were kept wet for 10-15 days and were hatched by submerging them in water. Larvae were fed a commercial fish food (Tetramin, Tetrawerke Co.). Adults at emergence were maintained on $10 \%$ dextrose solution under constant insectary conditions $\left(27 \pm 2^{\circ} \mathrm{C}\right.$ and $80 \pm 10 \%$ relative humidity).

Blood from a $D$. immitis naturally infected a 7 year-old castrated male mixed breed dog, captured at a heartworm focus in Niterói municipality, RJ, was used as a source for mf. The concentration of $\mathrm{mf}$ was 7,000 $\pm 500 \mathrm{ml}$ of blood as determined by five Giemsa-stained $20 \mu \mathrm{l}$ blood smears under 100x magnification, prior to mosquito feeding. Fresh microfilaremic dog blood was diluted with fresh human blood to adjust microfilaremia to 3,000 , 5,000 and $7,000 \mathrm{mf} / \mathrm{ml}$.

Four to six-day-old female mosquitoes were starved for $24 \mathrm{~h}$ prior to blood feeding. Four groups of 200 female mosquitoes were placed in tulle-covered cups. Three groups were allowed to feed on different densities of $\mathrm{mf}$ infected blood containing anticoagulant and the fourth group was fed on amicrofilaremic blood containing anticoagulant (control). Groups of female mosquitoes were provided with blood meals for 40 min containing 0 (control), 3,000, 5,000 or 7,000 mf/ml and maintained at $37^{\circ} \mathrm{C}$ in an artificial feeding apparatus (Rutledge et al. 1964). Blood feeding was performed simultaneously through an artificial membrane (Joseph Long Inc.) fixed to a glass apparatus.

Immediately after blood feeding, fully engorged mosquitoes were removed and ten engorged females per group were dissected to score ingested $\mathrm{mf}$. Dissection was performed by removing the midgut of each individual in a droplet of $0.6 \%$ saline solution on a glass slide covered with a coverslip, and examined under 100x magnification (Labarthe et al. 1998). The mean number of $\mathrm{mf}$ ingested by females was estimated by dividing the total number of $\mathrm{mf}$ within the midgut by the number of females dissected, in each group. The remaining mosquitoes were provided a $10 \%$ dextrose solution and kept at insectary conditions. Mortality was recorded daily and was evaluated for three periods: 0 to 2 days, 3 to 9 days and 10 to 13 days.

Development of $D$. immitis larvae was determined daily by dissecting subsamples of the surviving mosquitoes as described earlier. On the 13th day post-infection, all remaining specimens were dissected. After chloroform anesthesia, the head, mouthparts, midgut, Malpighian tubules and thorax of the mosquitoes were thoroughly examined under light microscope. Larvae found at different locations were scored and the developing filarial stages were classified according to Taylor (1960).

The mean number of third-stage larvae corresponds to the total number of larvae found on the head of the dissected mosquitoes divided by the total number of dissected mosquitoes for each $\mathrm{mf}$ concentration. The effect of the various mf densities on mortality of females was analized by chisquare. Vector efficiency index (Kartman 1954) was determined for each $\mathrm{mf}$ concentration offered to the mosquitoes as follows: mean no. $\mathrm{L}_{3} \times 100 /$ mean no. microfilariae ingested.

\section{RESULTS}

A total of 401 mosquitoes fed on blood containing D. immitis and 141 mosquitoes fed on 
amicrofilaremic blood (control). The mortality of mosquitoes between the first and the 13th day postinfection was $65.8 \%$ for the individuals fed on infected blood (264/401) and 9.9\% (14/141) of mosquitoes used as control. Mortality increased with $\mathrm{mf}$ infection $(\mathrm{p}<0.05)$. Considering mosquito mortality, post infection, for each period (0 to 2 days; 3-9 d; 10-13 d) among the three different mf concentrations, the only difference was observed within 0-2 days post infection group. The highest mortality during this period (64.6\%) was observed in the $7,000 \mathrm{mf} / \mathrm{ml}$ group when compared to the other two groups $(\mathrm{p}<0.05)$ and also when compared the total dead mosquitoes (Table I).

The infection rate of mosquitoes after ingestion of blood containing $3,000 \mathrm{mf} / \mathrm{ml}, 5,000 \mathrm{mf} /$ $\mathrm{ml}$ and $7,000 \mathrm{mf} / \mathrm{ml}$ were $55.3 \%, 66.7 \%$ and $100 \%$, respectively. The artificial feeding system used to infect the mosquitoes was shown to be efficient once $100 \%$ were infected $1 \mathrm{~h}$ and $24 \mathrm{~h}$ after repletion. Vector efficiency indices and mean number of ingested $\mathrm{mf}$ for each group are in Table II. The mean number of $\mathrm{mf}$ ingested by mosquitoes was influenced by $\mathrm{mf}$ densities in blood. Mosquitoes fed on blood containing 3,000 mf/ml, harbored a mean number of $12 \mathrm{mf}$ in the midgut, while at the higher concentration $(7,000 \mathrm{mf} / \mathrm{ml})$, a mean number of $42.9 \mathrm{mf}$ was recorded. Although only one mosquito of the $7,000 \mathrm{mf} / \mathrm{ml}$ group survived until day 11 post-infection, it harbored four third-stage larvae in the head (Table II).

The proportion of infected mosquitoes and the total number of larval worms decreased gradually after $48 \mathrm{~h}$. Melanized larvae were not found in any of the dissected mosquitoes (Table III).

There was no significant difference in the rate of worm development among the three different groups. "Sausage" stage larvae were recorded from

\section{TABLE I}

Mortality of Aedes aegypti, Rio de Janeiro laboratory strain, artificially infected on blood containing different densities of microfilariae (mf) of Dirofilaria immitis

\begin{tabular}{|c|c|c|c|c|c|c|}
\hline \multirow[b]{2}{*}{$\begin{array}{l}\text { Concentration } \\
\text { of } \mathrm{mf} / \mathrm{ml} \text { blood }\end{array}$} & \multicolumn{2}{|c|}{ Number of mosquitoes } & \multicolumn{4}{|c|}{ Mortality of mosquitoes } \\
\hline & Engorged & Dissected & $\begin{array}{c}0-2 \text { days }^{a} \\
(\%)\end{array}$ & $\begin{array}{c}\text { 3-9 days } \text { day }^{a} \\
(\%)\end{array}$ & $\begin{array}{c}10-13 \text { days }^{a} \\
(\%)\end{array}$ & $\begin{array}{l}\text { Total } \\
(\%)\end{array}$ \\
\hline 0 & 141 & 0 & $0 / 141$ & $\begin{array}{l}5 / 141 \\
(3.5)\end{array}$ & $\begin{array}{l}9 / 136 \\
(6.6)\end{array}$ & $\begin{array}{c}14 / 141 d \\
(9.9)\end{array}$ \\
\hline 3,000 & 162 & 76 & $\begin{array}{c}40 / 162 b \\
(24.7)\end{array}$ & $\begin{array}{c}38 / 122 \\
(31.1)\end{array}$ & $\begin{array}{l}8 / 84 \\
(9.5)\end{array}$ & $\begin{array}{c}86 / 162 \mathrm{e} \\
(53.1)\end{array}$ \\
\hline 5,000 & 126 & 42 & $\begin{array}{c}45 / 126 b \\
(35.7)\end{array}$ & $\begin{array}{l}37 / 81 \\
(45.7)\end{array}$ & $\begin{array}{l}2 / 44 \\
(4.5)\end{array}$ & $\begin{array}{c}84 / 126 \mathrm{e} \\
(66.7)\end{array}$ \\
\hline 7,000 & 113 & 19 & $\begin{array}{c}73 / 113 c \\
(64.6)\end{array}$ & $\begin{array}{c}21 / 40 \\
(52)\end{array}$ & $0 / 0$ & $\begin{array}{c}94 / 113 f \\
(83.2)\end{array}$ \\
\hline
\end{tabular}

$a$ : days post-infection; values in columns following by different letters are statisticaly different with $\mathrm{p} \leq 0.05$.

\section{TABLE II}

Infected and infective Aedes aegypti, Rio de Janeiro laboratory strain, number of uptaken microfilariae (mf) and vector efficiency index (VEI) of mosquitoes artificially infected on blood containing different densities of microfilariae of Dirofilaria immitis

\begin{tabular}{|c|c|c|c|c|c|c|}
\hline \multirow[b]{2}{*}{$\begin{array}{l}\text { Concentration of } \\
\mathrm{mf} / \mathrm{ml} \text { blood }\end{array}$} & \multicolumn{2}{|c|}{$1 \mathrm{~h}$ post-infection } & \multicolumn{2}{|c|}{$>11$ days post-infection } & \multirow{2}{*}{$\begin{array}{c}\text { Total } \\
\begin{array}{c}\text { Infection } \\
\text { rate }^{c}\end{array}\end{array}$} & \multirow[b]{2}{*}{ VEI $(\%)^{b}$} \\
\hline & $\begin{array}{l}\text { No. infected/ } \\
\text { dissected } \\
\text { mosq. }(\%)\end{array}$ & $\begin{array}{c}\overline{\mathrm{X}} \mathrm{mf} \\
\text { midgut/ } \\
\text { dissected mosq. }\end{array}$ & $\begin{array}{c}\text { No. infective/ } \\
\text { dissected } \\
\text { mosq. }(\%)^{a}\end{array}$ & $\begin{array}{c}\overline{\mathrm{X}} \mathrm{L}_{3} / \\
\text { dissected } \\
\text { mosq. }^{a}\end{array}$ & & \\
\hline 3,000 & $\begin{array}{l}10 / 10 \\
(100)\end{array}$ & 12 & $\begin{array}{l}6 / 20 \\
(30)\end{array}$ & 0.75 & $\begin{array}{c}55.3 \\
(42 / 76)\end{array}$ & 6.3 \\
\hline 5,000 & $\begin{array}{l}10 / 10 \\
(100)\end{array}$ & 15.4 & $\begin{array}{l}1 / 4 \\
(25)\end{array}$ & 0.25 & $\begin{array}{c}66.7 \\
(28 / 42)\end{array}$ & 1.6 \\
\hline 7,000 & $\begin{array}{l}10 / 10 \\
(100)\end{array}$ & 42.9 & $\begin{array}{c}1 / 1 \\
(100)\end{array}$ & 4 & $\begin{array}{c}100 \\
(19 / 19)\end{array}$ & 9.3 \\
\hline
\end{tabular}

$a$ : only third-stages larvae $\left(\mathrm{L}_{3}\right)$ found in head; $b$ : VEI $(\%)=\mathrm{X}$ no. $\mathrm{L}_{3}$ x $100 /$ mean no. mf ingested; $c$ : infection rate = no. infected mosq./no. dissected mosq. 
days $2-5$ post-infection and infective larvae were found in the head and proboscis of mosquitoes after day 11. Larval development within mosquitoes fed on blood with different densities of mf was not completely synchronous, as more than one stage of the parasite was commonly present in a single mosquito host.

\section{TABLE III}

Larvae number and its local in Aedes aegypti, Rio de Janeiro laboratory strain, artificially infected by Dirofilaria immitis microfilariae

\begin{tabular}{|c|c|c|c|}
\hline & $\begin{array}{l}\text { No. infected/ } \\
\text { dissected (\%) }\end{array}$ & Local & $\begin{array}{r}\text { No. } \\
\text { larvae }\end{array}$ \\
\hline 1 h PI & $\begin{array}{l}30 / 30 \\
(100)\end{array}$ & midgut & 703 \\
\hline 1-2 days PI & $\begin{array}{l}22 / 24 \\
(91.7)\end{array}$ & midgut/cells MT & 282 \\
\hline 3-9 days PI & $\begin{array}{l}27 / 55 \\
(49.1)\end{array}$ & MT & 108 \\
\hline 10-13 days PI & $\begin{array}{l}11 / 28 \\
(39.3)\end{array}$ & MT/HD/PB & 34 \\
\hline
\end{tabular}

Total 90/137

PI: post-infection; MT: Malpighian tubules; HD: head; PB: proboscis

\section{DISCUSSION}

The development of D. immitis in Ae. aegypti, Rio de Janeiro laboratory strain, proceeded more rapidly than in other surveys where Rock strain, Vero Beach strain, BLACK-EYE strain, Liverpool strain and Queensland strain of Ae. aegypti were used (Taylor 1960, Buxton \& Mullen 1981). Although larvae development speed is highly dependent on temperature (Kutz \& Dobson 1974, Christensen \& Hollander 1978), some differences may have occurred among protocols, even though all studies reported the same laboratory conditions, including temperature. The development of the parasite can also vary within mosquito species (Frimeth \& Arai 1983) and therefore the genetic diversity of different strains of the same species could be the cause of such variation. Larval development was not arrested, which may be interpreted as this strain's incapacity of controling worm burden and therefore potentially harboring high numbers of worms resulting in high mortality.

According to observations by Knaus et al. (1993), when Ae. aegypti bloodfeed, they ingest from 1.5 to $4.2 \mu \mathrm{l}$ of blood. The relationship between the actual and the expected intake of $\mathrm{mf}$ was observed after dissection of mosquitoes $1 \mathrm{~h}$ after infection. However, mosquitoes fed on blood containing $7,000 \mathrm{mf} / \mathrm{ml}$ ingested approximately two times the expected number. This result contrasts with the report of Kershaw et al. (1955), where Ae. aegypti ingested only a little more than half the number of $\mathrm{mf}$ that would be expected, but is comparable with the results of Nayar and Sauerman (1975) where the number of mf per female was approximately the expected number. This phenomenon may have influenced the high mortality observed in the group bloodfed with the higher densities of $\mathrm{mf}$, mainly the first 2 days post-infection. The ingestion of a larger number of mf can substantially increase the number of third-stage larvae that develops (Lowrie 1991). As observed in this survey, at the higher $\mathrm{mf}$ concentration there is a strong negative correlation between the number of filariae in the tubules and the survival of the host mosquito (Christensen 1978). Mortality rates of mosquitoes that ingested the two lowest densities of mf was significantly lower than the group of $7,000 \mathrm{mf} / \mathrm{ml}$. Furthermore the mean number of $\mathrm{L}_{3}$ recorded was lower than the $7,000 \mathrm{mf} / \mathrm{ml}$, although the higher mf concentration had only one mosquito surviving after 11 days post infection, suggesting that mosquitoes can support the development of some larvae.

The higher production of $\mathrm{L}_{3}$ in the group of $3,000 \mathrm{mf} / \mathrm{ml}$ than in the two other groups that ingested higher numbers of mf may be due to the high mortality observed when large numbers of $\mathrm{mf}$ invade the Malpighian tubule cells (Weiner \& Bradley 1970). Therefore, ingestion of low numbers of $\mathrm{mf}$ increases mosquito survival and consequent development of $\mathrm{L}_{3}$.

According to Kartman (1953) mosquitoes fed through a membrane on infectious blood containing anticoagulant increase the rate of mf migration from the midgut to the Malpighian tubules. This procedure prevents the rapid coagulation of the blood in the stomach of Ae. aegypti, since this species does not have anticoagulin (Metcalf 1945). Therefore, the infection rate of mosquitoes dissected $1 \mathrm{~h}$ post-infection was $100 \%$. However, 3 days post-infection when the number of larvae found in the cells of the Malpighian tubules was compared to the number of ingested $\mathrm{mf}$, there was a drastic reduction in larvae number, indicating that the majority of them were destroyed. In some species of mosquitoes (e.g. Ae. aegypti) mf enter the Malpighian tubules cells but fail to develop (Buxton \& Mullen 1981, Sauerman \& Nayar 1985) and are quickly excreted after entering (Nayar \& Sauerman 1975, Lowrie 1991). The proportion of mosquitoes harboring worms decreased over time, $1 \mathrm{~h}$ was $100 \%$ and after 13 days post infection only $39.3 \%$ of the mosquitoes were infected. Buxton 
and Mullen (1981) also recorded similar rates for the same species but in a strain considered intermediate in its susceptibility while Apperson et al. (1989) found $85 \%$ of the mosquitoes became infected belonging to a susceptible strain while only $58 \%$ of the refractory strain became infected.

The vector efficiency indices for Ae. aegypti used in the present survey ranged from 1.6 to 9.3. Considering these values, some authors (Kartman 1953, Sulaiman 1983) would consider this strain Ae. aegypti as refractory. Other factors, that have been considered to characterize the degree of resistance of a strain, like arrested development of $\mathrm{mf}$ in the mosquitoes, was not observed in this survey. Genetic factors also play a role in susceptibility and may be involved in different degrees of susceptibility of strains of the same species of mosquitoes from different geographic areas. Also, differences in D. immitis infectivity and mosquito species strains must be considered. The finding of $\mathrm{L}_{3}$, infection rates and vector efficiency recorded in this paper suggest that the suitability of the $A e$. aegypti, Rio de Janeiro laboratory strain, as a host and subsequent vector potential, is low. A 10-yearold laboratory strain that may no longer reflect the true genetic susceptibility and capacity for the natural population was used. For this reason, comparisons between this strain and an $\mathrm{F}_{1}$ population of Ae. aegypti from this area may enlighten the vector efficiency of this species in nature, although, previous studies (Lourenço-de-Oliveira \& Deane 1995, Labarthe et al. 1998a,b) never found an infected Ae. aegypti in the Rio de Janeiro.

\section{ACKNOWLEDGEMENTS}

To Luciana Barros and Dinair Couto Lima for the assistance in rearing the mosquitoes.

\section{REFERENCES}

Ahid S, Padua SV, Lourenço-de-Oliveira R 2000. Vector competence of Culex quinquefasciatus Say from different regions of Brazil to Dirofilaria immitis. Mem Inst Oswaldo Cruz 95: 769-775.

Apperson CS, Engber B, Levine JF 1989. Relative suitability of Aedes albopictus and Aedes aegypti in North Carolina to support development of Dirofilaria immitis. J Am Mosq Control Assoc 5: 377-382.

Brito AC, Fontes G, da Rocha EMM, Rocha DAM, Regis L 1999. Development of Dirofilaria immitis (Leidy) in Aedes aegypti (L.) and Culex quinquefasciatus (Say) from Maceió, Alagoas, Brazil. Mem Inst Oswaldo Cruz 94: 575-576.

Bryan JH, Oothamn P, Andrews BJ, McGreevy PB 1974. Effects of pharyngeal armature of mosquitoes on microfilariae of Brugia pahangi. Trans $R$ Soc Trop Med Hyg 68: 14.

Buxton BA, Mullen GR 1981. Comparative susceptibility of four strains of Aedes aegypti (Diptera: $\mathrm{Cu}-$ licidae) to infection with Dirofilaria immitis. J Med Entomol 18: 434-440.

Chellappah WT, Chellappah Jr GR 1968. Susceptibility of four common Singapore mosquitoes to Dirofilaria immitis Leidy. J Med Ent 5: 358-361.

Christensen BM 1978. Dirofilaria immitis: effect on the longevity of Aedes trivittatus. Exp Parasitol 44: 116123.

Christensen BM 1981. Observations on the immune response of Aedes trivittatus against Dirofilaria immitis. Trans R Soc Trop Med Hyg 75: 439-443.

Christensen BM, Andrews WN 1976. Natural infection of Aedes trivittatus (Coq.) with Dirofilaria immitis in central Iowa. J Parasitol 62: 276-280.

Christensen BM, Hollander AL 1978. Effect of temperature on vector-parasite relationships of Aedes trivittatus and Dirofilaria immitis. Proc Helminthol Soc Washington 45: 115-119.

Christensen BM, Sutherland DR 1984. Defense reactions of mosquitoes to filarial worms: comparative studies on the response of three different mosquitoes to inoculated Brugia pahangi and Dirofilaria immitis microfilariae. J Invert Pathol 44: 267-274.

Christensen BM, Huff BM, Miranpuri GS, Harris KL, Christensen LA 1989. Hemocyte population changes during the immune response of Aedes aegypti to inoculated microfilariae of Dirofilaria immitis. $J$ Parasitol 75: 119-123.

Frimeth JP, Arai HP 1983. Some potential mosquito vectors of the canine heartworm, Dirofilaria immitis, in the Calgary region of southern Alberta. Can J Zool 61: 1156-1158.

Kartman L 1953. Factors influencing infection of the mosquito with Dirofilaria immitis (Leidy, 1856). Exp Parasitol 2: 27-78.

Kartman L 1954. Suggestions concerning an index of experimental filaria infection in mosquitoes. Am J Trop Med Hyg 3: 329-337.

Kasai N, Williams P 1986. Infecção experimental de Aedes fluviatilis (Lutz, 1904) por Dirofilaria immitis (Leidy, 1856). Rev Brasil Biol 46: 277-283.

Kershaw WE, Lavoipierre MMJ, Beesley WN 1955. Studies on the intake of microfilariae by their insect vectors, their survival, and their effect on the survival of their vectors VII - Further observations on the intake of the microfilariae of Dirofilaria immitis by Aedes aegypti in laboratory conditions: the pattern of the intake of a group of flies. Ann Trop Med Parasitol 49: 203-211.

Kershaw WE, Lavoipierre MMJ, Chalmers TA 1953. Studies on the intake of microfilariae by their insect vectors, their survival, and their effect on the survival of their vectors. Ann Trop Med Parasitol 47: 207-224.

Knaus RM, Foil LD, Issel CJ, Leprince DJ 1993. Insect blood meal studies using radiosodium $24 \mathrm{Na}$ and 22 Na. J Am Mosq Control Assoc 9: 246-268.

Kutz FW, Dobson RC 1974. Effects of temperature on the development of Dirofilaria immitis (Leidy) in Anopheles quadrimaculatus Say and on vector mortality resulting from this development. Ann Entomol Soc Am 67: 325-331. 
Labarthe N, Serrão ML, Melo YF, Oliveira SJ, Lourençode-Oliveira R 1998a. Potential vectors of Dirofilaria immitis (Leidy, 1856) in Itacoatiara, oceanic region of Niterói municipality, State of Rio de Janeiro, Brazil. Mem Inst Oswaldo Cruz 93: 425-432.

Labarthe N, Serrão ML, Melo YF, Oliveira SJ, Lourenço-de-Oliveira R 1998b. Mosquito frequency and feeding habits in an enzootic canine dirofilariasis area in Niterói, State of Rio de Janeiro, Brazil. Mem Inst Oswaldo Cruz 93: 145-154.

Leidy J 1856. A synopsis of Entozoa and some of their ecto-congeners observed by the author. Proc Ac Natl Sc Philadelphia 8: 42-58.

Lindemann BA 1977. Dirofilaria immitis encapsulation in Aedes aegypti. Mosq News 37: 293-294.

Lourenço-de-Oliveira R, Deane L 1995. Presumed Dirofilaria immitis infections in wild-caught Aedes taeniorhynchus and Aedes scapularis in Rio de Janeiro, Brazil. Mem Inst Oswaldo Cruz, 90: 387-388.

Lowrie RC 1991. Poor vector efficiency of Culex quinquefasciatus following infection with Dirofilaria immitis. J Am Mosq Control Assoc 7: 30-36.

Ludlam KW, Jachowski LA, Otto GF 1970. Potential vectors of Dirofilaria immitis. JAVMA 157: 13541359.

Macêdo FC, Labarthe N, Lourenço-de-Oliveira R 1998. Susceptibility of Ae. scapularis (Rondani, 1848) to Dirofilaria immitis (Leidy, 1856), an emerging zoonosis. Mem Inst Oswaldo Cruz 93: 435-437.

McGreevy PB, Bryan JH, Oothuman P, Kolstrup N 1978. The lethal effects of the cibarial and pharyngeal armatures of mosquitoes on microfilariae. Trans $R$ Soc Trop Med Hyg 72: 361-368.

Metcalf RL 1945. The physiology of the salivary glands of Anopheles quadrimaculatus. J Natl Malaria Soc
4: 271-278.

Nayar JK, Sauerman DM 1975. Physiological basis of host susceptibility of Florida mosquitoes to Dirofilaria immitis. J Insect Physiol 21: 1965-1975.

Rutledge LC, Ward RA, Gould DJ 1964. Studies on the feeding response of mosquitoes to nutrictive solutions in a new membrane feeder. Mosq News 24: 407-419.

Sauerman DM, Nayar JK 1983. A survey for natural potential vectors of Dirofilaria immitis in Vero Beach, Florida. Mosq News 43: 222-225.

Sauerman Jr DM, Nayar JK 1985. Characterization of refractoriness in Aedes aegypti (Diptera: Culicidae) to infection by Dirofilaria immitis. J Med Entomol 22: 94-101.

Sulaiman I 1983. Susceptibility of Aedes aegypti to infections with Dirofilaria immitis and Dirofilaria repens. Southeast Asian J Trop Med Pub Hlth 14: 543-547.

Talluri VM, Cancrini G 1994. An ultrastructural study on the early cellular response to Dirofilaria immitis (Nematoda) in the malpighian tubules of Aedes aegypti (refractory strains). Parasite 1: 343-348.

Taylor AE 1960. The development of Dirofilaria immitis in the mosquito Aedes aegypti. J Helminthol 34: 27 38.

Tolbert RH, Johnson Jr WE 1982. Potential vectors of Dirofilaria immitis in Macon County, Alabama. Am $J$ Vet Res 43: 2054-2056.

Webber WA, Hawking F 1955. Experimental maintenance of Dirofilaria repens and D. immitis in dog. Exp Parasitol 4: 143-164.

Weiner DJ, Bradley RR 1970. Ability of some mosquitoes to transmit Dirofilaria immitis in Florida. Mosq News 30: 406-410. 